\section{Assisted conception and retinopathy of prematurity: 8-year follow-up study}

CL Funnell and TR Dabbs

\section{Abstract}

Aims To assess the effect of assisted conception (AC) on retinopathy of prematurity (ROP) and ROP screening. Follow-up to the study by McKibbin et al.

Methods Retrospective study utilising computerised databases of ROP screening, live births, AC and multiple births between 1st April 2000 and 31st August 2003 at St James's Hospital (SJUH) Leeds. $\chi^{2}$ tests of significance were used.

Results ROP screening was undertaken in $11 / 265$ (4.2\%) of AC births versus $1.6 \%$ of all SJUH births. This is significantly less than the $20.3 \%$ of AC babies screened in McKibbin et al study $(P=<0.01)$. There was no ROP detected in the $11 \mathrm{AC}$ babies. Of all AC births, $36.9 \%$ were one of twins and $1.5 \%$ from triplet births compared to $46.0 \%$ one of twins and $18.6 \%$ one of triplets in McKibbin's study. Conclusions The percentage of AC babies requiring $R O P$ screening has fallen since McKibbin et al study which was performed between August 1991 and December 1994. This appears to be at least partially due to the reduced multiple birth rates. This reduction in the multiple birth rates follows evidence that reducing the number of embryos transferred does not reduce the number of couples taking home a baby and Human Fertility and Embryology Association guidelines recommending 'no more than two embryos should be transferred in an IVF cycle'. Changes in clinical practice at SJUH have significantly reduced the likelihood of AC babies requiring ROP screening and developing ROP.

Eye (2007) 21, 383-386. doi:10.1038/sj.eye.6702215; published online 13 January 2006

Keywords: assisted conception retinopathy prematurity; screening triplets
Introduction

Assisted conception (AC) over the last two decades has resulted in a large increase in the number of multiple births. In 1996, McKibbin et $\mathrm{al}^{1}$ reported in Eye that AC techniques had increased the number of babies fulfilling the Royal College of Ophthalmologists guidelines for retinopathy of prematurity (ROP) screening (less than $1500 \mathrm{~g}$ and/or less than 32 weeks gestation) at St James's hospital (SJUH), Leeds. $20.3 \%$ of babies born as a result of AC techniques in the period between August 1991 and December 1994 fulfilled the screening criteria compared to $1.65 \%$ of all live births in this period. $16.5 \%$ of all babies screened in this period were born as a result of AC. ${ }^{1}$

Over recent years there has been increasing body of research showing that limiting embryo transfer during in vitro fertilisation (IVF) does not reduce the number of couples taking home a baby. ${ }^{2-5}$ The Human Fertility and Embryology Association (HFEA) published guidelines in 2001 recommending that 'no more than two embryos should be transferred in an IVF cycle except in exceptional circumstances', where a three embryo transfer may be performed. ${ }^{6}$

The aim of this study was to see if this new evidence had altered the incidence of ROP associated with AC. This study is a follow-up study to that performed by McKibbin et $a l^{1}$ at SJUH in $1996{ }^{1}$

\section{Methods}

ROP screening findings at SJUH were entered into a database at the time of the examination. This retrospective study utilised this database to find the number of babies screened for ROP between 1st April 2000 and 31st August 2003. This 3 years and 5 months period was the same length of time as in McKibbin's study. The total number of live births, live AC births and multiple births at SJUH were found from
Department of

Ophthalmology, Leeds Teaching Hospitals Trust, Leeds,

Yorkshire, UK

Correspondence:

CL Funnell, Department of Ophthalmology, Chancellor Wing, St James's Hospital, Beckett Street, Leeds, Yorkshire LS9 7TF, UK Tel: +44 113206 4741; Fax: +441132065748. E-mail: c.l.funnell@ doctors.org.uk

Received: 4 July 2005 Accepted in revised form: 18 October 2005 Published online: 13 January 2006 
computerised records in the $\mathrm{AC}$ and neonatal departments.

The incidence of multiple births, the percentage of AC births requiring ROP screening and the incidence of ROP were compared with the 1996 study. $\chi^{2}$ of significance were used.

\section{Results}

There were 790 babies born as a result of $\mathrm{AC}$ techniques at SJUH in the study period between 1st April 2000 and 31st August 2003. Of these babies, 60.3\% (477) were singletons, $36.9 \%$ (292) were one of twins and $1.5 \%$ (12) were triplets. (Table 1) (Figure 1) Of the AC babies $38.9 \%$ (308) were born as a result of IVF, 29.7\% (235) from intracytoplasmic sperm injection, and 31.2\% (247) from other forms of AC. Of the 790, 265 babies resulting from the AC techniques at SJUH were born at SJUH. This study will concentrate on these babies as our retinopathy screening data is limited to those babies born and screened at SJUH.

In all, 248 babies were screened for ROP during the study period 1st April 2000 and 31st August 2003. Of these $206(83 \%)$ were born at SJUH. There were 12737 live births at SJUH during the study period. Therefore, $1.6 \%$ of all SJUH births required ROP screening. There were 11 AC babies born and screened for ROP at SJUH. These included four sets of twins (eight babies). ROP screening was therefore undertaken in $4.2 \%(11 / 265)$ of AC births (11 out of the $265 \mathrm{AC}$ babies born at SJUH).

(Table 1) (Figure 2)

There was no ROP detected in any of the $11 \mathrm{AC}$ babies screened for ROP after birth at SJUH. 13.3\% (33 of the 248) of babies screened during the study period had ROP. In all, 14 had stage 1, 10 stage 2 and nine stage 3 disease. Of those born at SJUH 12.6\% (26/206) developed ROP.

\section{Discussion}

This study shows a reversal of the trend towards increasing ROP screening as a result of AC. In all, $4.2 \%$ of
AC births required screening in this study, significantly less than the $20.3 \%$ found by McKibbin et $a l^{1}$ at the same hospital between August 1991 and December 1994. $(P=<0.01)$ (Figure 2) Population-based studies have shown that around $1 \%$ of babies require screening for ROP. $^{7-8}$ This is similar to the $1.65 \%$ found in McKibbin et $a l^{1}$ study and the $1.6 \%$ found in this study. AC babies therefore still have a higher likelihood of requiring ROP screening but this is much less pronounced than previously reported. This reduction in the need for screening is due to the reduced percentage of AC babies born at less than $1500 \mathrm{~g}$ and less 32 weeks gestation. In this study, there were no cases of ROP in any of the AC babies screened. This was probably due to the small number of babies in this group.

The introduction of $\mathrm{AC}$ techniques resulted in increased numbers of multiple births. In the UK in the $1998 / 9$ period, $46 \%$ of babies born as a result of in vitro

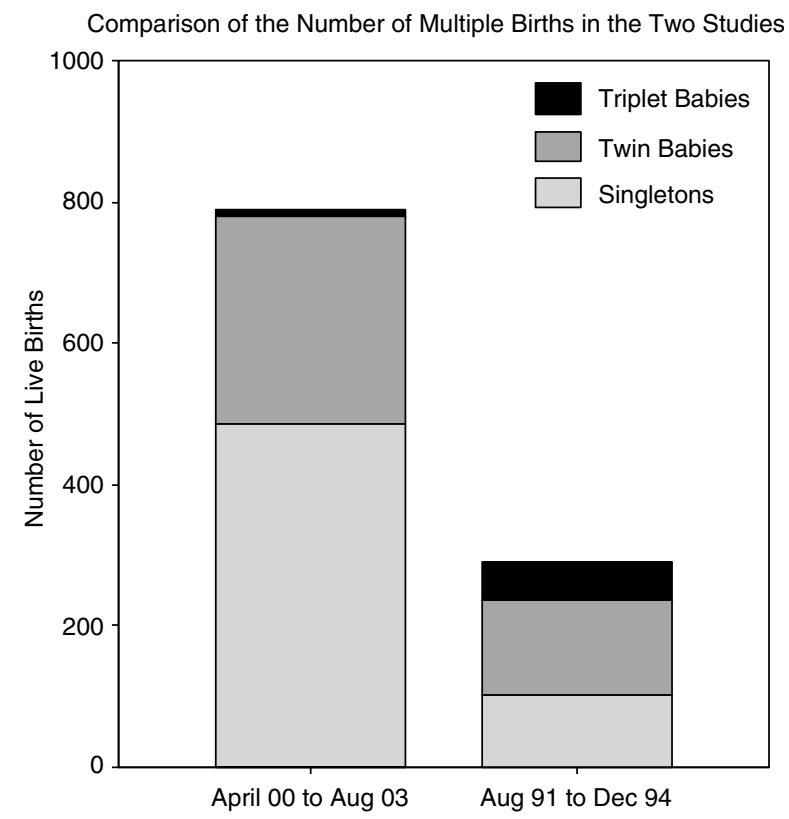

Figure 1 Comparison of the number of multiple births in the two studies.

Table 1 Summary of results

\begin{tabular}{lcc}
\hline & $\begin{array}{c}\text { St James's Hospital } \\
\text { April 2000-August 2003 }\end{array}$ & $\begin{array}{c}\text { St James's Hospital } \\
\text { August 1991-December 1994 }\end{array}$ \\
\hline Total number of live births & 12737 & 16208 \\
Number of Assisted Conception Births & 790 & 291 \\
& 265 born at SJUH & 248 \\
Number babies screened for ROP at SJUH & 206 born at SJUH & 267 \\
Percentage of SJUH Assisted Conception babies requiring ROP Screening & $4.2 \%(11 / 265)$ & $20.3 \%(59 / 291)$ \\
Number of twin birth in assisted conception babies & $36.9 \%(292 / 790)$ & $46.0 \%(134 / 291)$ \\
Number of triplet births in assisted conception babies & $1.5 \%(12 / 790)$ & $18.6 \%(54 / 291)$ \\
\hline
\end{tabular}


Comparison of ROP Screening in the Two Studies

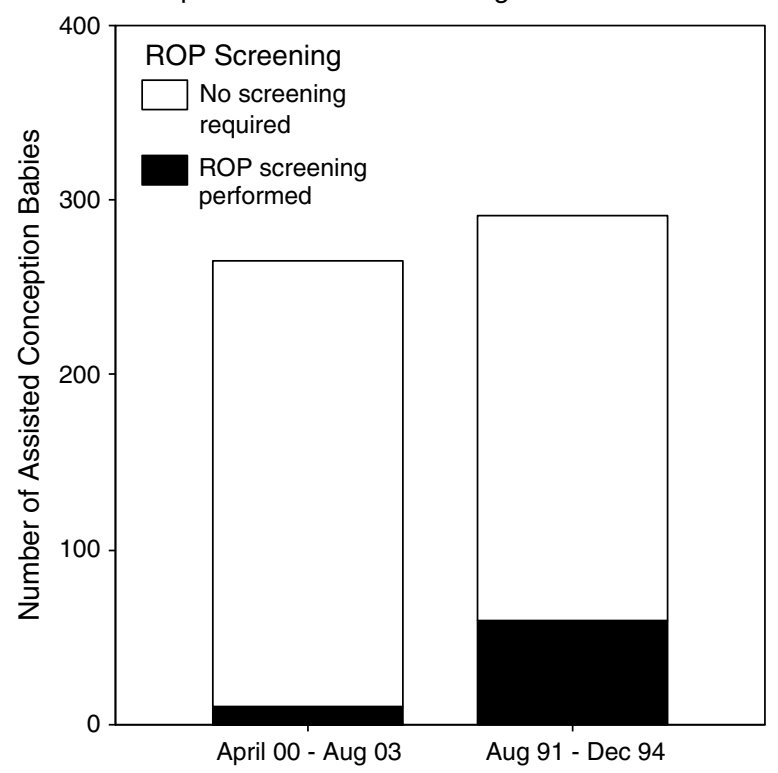

Figure 2 Comparison of ROP screening in the two studies.

fertilisation were from multiple pregnancies. ${ }^{6}$ Of all higher order pregnancies, $69 \%$ were due to $\mathrm{AC}$ techniques (34\% ovarian stimulation, $24 \%$ IVF and $11 \%$ gamete intrafallopian transfer). ${ }^{3}$ The rate of triplet or higher order multiple births increased by $430 \%$ in the UK between the mid 1970s and 1998. ${ }^{9}$ High multiple pregnancy rates occurred as clinics attempted to increase their success rate per cycle of treatment. There has been mounting evidence, however, that reducing the number of embryos transferred does not reduce the percentage of women giving birth. ${ }^{2}$ Templeton and Morris ${ }^{4}$ found that reducing the embryos transferred to two reduced the likelihood of multiple pregnancy without reducing the chance of having a baby. Other studies have found that transfer of three rather than two embryos did not improve the pregnancy rate. ${ }^{2,5,10}$ The birth rate appears to be related to the number of eggs fertilised, rather than the number transferred (a measure of embryo quality). ${ }^{5}$ This led to the UK Human Fertility and Embryology Authority (HFEA) database recommending that 'no more than two embryos should be transferred in an IVF cycle except in exceptional circumstances ${ }^{\prime}{ }^{6}$ After years of increasing multiple birth rates, there is now evidence that the rate of higher order multiple pregnancies is now reducing. ${ }^{11}$

Higher order pregnancy babies are at a particular risk of developing ROP as they are frequently born early (47\% of triplets are delivered before 32 weeks) and of low birth weight. $^{2}$ The ROP rates in triplets has been reported to be significantly higher than in both singletons and twins. ${ }^{12}$ Multiple pregnancies are associated with an increased risk of developing threshold ROP. ${ }^{13}$ The higher incidence of prematurity in AC births is primarily explained by the greater number of multiple births in this group. ${ }^{14}$

McKibbin's study, between August 1991 and December 1994, found that $46.0 \%$ of babies born after AC were one of twins and $18.6 \%$ one of triplets. In this study, the rates have fallen to $36.9 \%$ one of twins and $1.5 \%$ from triplet births (Figure 1). This is a significant reduction in the number of multiple births $(P<0.01)$. The reduction in triplets is particularly marked and is evidence of the change in practice which has occurred in accordance with the Human Fertility and Embryology guidelines. ${ }^{6}$ This reduction in AC multiple births appears to be the reason for the fall in the number of $\mathrm{AC}$ babies requiring screening at SJUH. This drop in babies requiring screening should be mirrored by a reduction in the number of AC babies developing ROP and potentially losing vision.

The reduction in ROP screening in AC may also be partly due to improvements in antenatal care, resulting in fewer children being born very prematurely. These interventions include cerclage (suturing of the incompetent cervix) the detection and treatment of infections and the use of progesterone. ${ }^{15}$ It is hoped that improved treatment of premature babies will eventually stop ROP developing. At present, however, the incidence of ROP seems to be similar to that occurring back in 1980s at the time of the CRYO-ROP study. ${ }^{16}$ Worryingly Hameed et $a l^{17}$ in Leicester reported an increase in severe ROP in babies between the early 1990s and the late 1990s. Conrath et al, ${ }^{18}$ however, reported more promising results with rates reducing. It appears that smaller sicker babies are now surviving long enough to develop ROP and are off setting the general improvement. These mixed results make it difficult to assess how much of the change in ROP found is this study was due to factors other than AC.

This study was retrospective and this limited the data available. ROP screening data was only available on AC babies born at SJUH. The study by McKibbin et al ${ }^{1}$ also used data collected on AC babies born in other hospitals. This was not available for this study. AC is a specialised service, not provided by all trusts. Many women go back to their local hospitals to have their babies and therefore only 265 of the 790 AC babies were included in the study. In the study by McKibbin et $a l^{1} 42$ out of 291 AC babies were born at St James's. In the unusual case that there were no beds available, babies born at St James's may have been transferred to other neonatal units. This is unlikely to have occurred with those at risk of ROP as it is usually the larger, less sick babies which are transferred out of St James's. There were no babies in which a transfer started after screening was commenced. 
We wish to acknowledge the invaluable support of Mrs Sharma, Consultant Obstetrician SJUH Leeds, Ms Bhuija SpR and their team for providing the data for this study and their continuing clinical assistance.

\section{References}

1 McKibbin M, Dabbs TR. Assisted conception and retinopathy of prematurity. Eye 1996; 10: 476-478.

2 Wimalasundera RC, Trew G, Fisk NM. Reducing the incidence of twins and triplets. Best PractRes Clinl Obstret Gynecol 2003; 17(2): 309-329.

3 Levene MI, Wild J, Steer P. Higher multiple births and the modern management of infertility in Britain. $\mathrm{Br} J$ Obstet Gynaecol 1992; 99: 607-613.

4 Templeton A, Morris JK. Reducing the risk of multiple births by the transfer of two embryos after in vitro fertilisation. N Engl J Med 1992; 339: 573-577.

5 Staessen C, Janssenwillen C, Van den Abbeel E, Devroey P, Van Steirtegham AC. Avoidance of triplet pregnancies by elective transfer of two good quality embryos. Hum Reprod 1993; 8: 1650-1653.

6 Human Fertilisation \& Embryology Authority. 2001 Annual Report. Stationary Office: London, 2001.

7 Maly E. Frequency and natural history of retinopathy of prematurity: a prospective study in a Swedish city 1986-1990. Acta Ophthalmol (Copenhagen) 1993; 210(Suppl): 52-55.

8 Barnekow BB, Stigman G. Retinopathy of prematurity in the southern part of Sweden. Acta Ophthalmol (Copenhagen) 1993; 210(Suppl): 48-51.

9 Blondel B, Kaminski M. Trends in the occurrence, determinants, and consequences of multiple births. Semin Perinatol 2002; 26(4): 239-249.
10 Devreker F, Emiliani S, Revelard P. Comparison of two elective transfer polices to two embryos to reduce multiple pregnancies without impairing pregnancy rates. Hum Reprod 1999; 14: 83-89.

11 Roberts CL, Raynes-Greenow CH, Algert CS, Peat B. Higher order multiple pregnancies in New South Wales 1990-1999. Aust N Z J Obstet Gynaecol 2002; 42(1): 51-54.

12 Kaufman GE, Malone FD, Harvey-Wilkes KB, Chelmow D, Penzians AS, D'Alton ME. Neonatal morbidity and mortality associated with triplet pregnancy. Obstet Gynecol 1998; 91(3): 342-348.

13 Blumenfeld LC, Siakowski RM, Johnson RA, Feuer WJ Flynn JT. Retinopathy of prematurity in multiple-gestation pregnancies. Am J Ophthal. 1998; 125: 197-203.

14 Bergh T, Ericson A, Hillensjo T, Nygren KG, Wennerholm UB. Deliveries and children born after in-vitro fertilisation in Sweden 1982-95: a retrospective cohort study. Lancet 1999; 354: 1579-1585.

15 Hollier LM. Preventing preterm birth: what works, what doesn't. Obstet Gynecol Survey 2005; 60(2): 124-131.

16 Good WV, Hardy RJ, Dobson V, Palmer EA, Phelps DL, Quintos $\mathrm{M}$ et al., Early Treatment for Retinopathy of Prematurity Cooperative Group. The incidence and course of retinopathy of prematurity: findings from the early treatment for retinopathy of prematurity study. Pediatrics 2005; 116(1): 15-23.

17 Hameed B, Shyamanur K, Kotecha S, Manktelow BN, Wooddruff G, Draper ES et al. Trends in the incidence of severe retinopathy of prematurity in a geographically defined population over a 10-year period. Pediatrics 2004; 113(6): 1653-1657.

18 Conrath JG, Hadjadj EJ, Forzano O, Denis D, Millet V, Lacroze $\mathrm{V}$ et al. Screening for retinopathy of prematurity: results of a retrospective 3-year study of 502 infants. J Pediatr Ophthalmol Strabismus 2004; 41(1): 31-34. 